\title{
Análise de critérios e requisitos para o acesso a Obras Raras em bibliotecas digitais - um estudo longitudinal
}

\author{
Ana Flávia Lucas de Faria Kama \\ Mestre; Universidade de Brasília (UnB), Brasília, DF, Brasil; \\ fariakama@hotmail.com \\ Miriam Paula Manini \\ Doutora; Universidade de São Paulo (USP), São Paulo, SP, Brasil; \\ mpmanini@uol.com.br \\ Dulce Maria Baptista \\ Doutora; Universidade de Brasília (UnB), Brasília, DF, Brasil; \\ baptistadm368@gmail.com
}

\begin{abstract}
Resumo: Coleções de Obras Raras são de suma importância para o conhecimento histórico humano. Ao longo dos anos a digitalização desse tipo de coleção e sua disponibilização na internet vêm se mostrando como uma alternativa eficaz ao seu acesso diante dos avanços da preservação digital e da curadoria digital. $\mathrm{O}$ presente estudo tem como objetivo analisar os critérios e requisitos de acesso a obras raras digitalizadas em dez bibliotecas digitais do Brasil e do mundo, dotado de uma natureza longitudinal e partindo de uma metodologia mista, com coletas de dados realizadas em 2010 e 2015 dentro da amostra selecionada. Os resultados mostram que houve uma evolução na qualidade do acesso e do tratamento das Obras Raras digitalizadas presentes na amostra, de modo a concluir, que a digitalização de Obras Raras obteve um acréscimo de qualidade, sendo feita de forma mais coesa e com requisitos mais padronizados.
\end{abstract}

Palavras-chave: Obras Raras. Digitalização de Obras Raras. Biblioteconomia de livros raros. Bibliotecas digitais. Preservação digital. Curadoria digital.

\section{Introdução}

A história da formação da inteligência e da cultura do ser humano perpassa a história do suporte informacional - objeto ou instrumento - mais bem-sucedido de que se tem notícia: o livro. No decorrer de sua trajetória, o livro foi ressignificado diante das tecnologias acessíveis em cada época. De peles de 
animais a estruturas vegetais, o livro chegou ao século XXI também de forma binária e virtual.

É sabido que é por meio de fatos e de costumes que se constrói a história humana (THOMPSON, 1998); o livro é um dos principais instrumentos para que se tenha acesso a esses fatos. Desta forma, esse objeto cultural recebe uma importância rígida e indiscutível diante da formação presente e futura daqueles que almejam o entendimento dos fatos e costumes que os circundam e que planejam compreender o futuro.

Um dos "tipos" de livro que mais servem ao objetivo de reconstrução da memória humana são os ditos livros raros (PINHEIRO, 1989), logo, a importância desse tipo de documento dentro das coleções de bibliotecas ao redor do mundo é latente. Seu acesso e sua preservação devem ser pesquisados e estudados pela sociedade acadêmica, técnica e científica a fim de proporcionar meios eficazes para seu uso e para a apreciação pelo público. Um dos cuidados que cercam as Obras Raras é justamente o seu acesso. Esse é um tema que sempre envolve polêmicas quando discutido e analisado: como proporcionar a disseminação de Obras Raras se seu acesso deve ser controlado? Uma das respostas a esse dilema chegou com a tecnologia da digitalização.

Obras Raras digitalizadas e disponibilizadas em bibliotecas digitais poderiam suprir, em parte, a demanda de acesso da maioria dos usuários interessados nesse tipo de acervo. A digitalização de Obras Raras já é realidade desde fins da década de 90 do século passado. Mas é preciso analisar o modo como tanto a gestão quanto a disponibilização dessas obras está sendo feito dentro dos portais das bibliotecas digitais.

Por meio de um estudo de natureza longitudinal, este artigo pretende analisar os critérios e requisitos de acesso a Obras Raras digitalizadas em dez bibliotecas digitais do Brasil e do mundo. Será que o acesso aos nossos tesouros impressos evoluiu por trás das telas cristalizadas dos computadores e smartphones?

A estrutura do artigo contará com uma breve contextualização e revisão de literatura da área sobre o conceito de Obras Raras, a importância da digitalização desse tipo de acervo e a contextualização dessa atividade dentro da 
preservação digital e da curadoria digital. Em seguida será identificada a metodologia da pesquisa, bem como a amostra selecionada para as duas análises realizadas. Na quarta parte do artigo serão apresentados os dados da coleta e sua análise, encaminhando-se então para as conclusões do estudo.

\section{Obras raras e digitalização}

Não há exatamente um consenso acerca do conceito de Obras Raras na literatura da área. Pinheiro (1989) defende que os critérios de definição e seleção devem ater-se a grandes grupos, quais sejam limites históricos, aspectos bibliológicos, valor cultural e valor financeiro. A grande maioria das políticas de definição de Obras Raras das bibliotecas, portanto, passariam por esses grandes grupos ao adotar seus critérios para seleção de Obras Raras.

Ademais, Pinheiro (1989) continua problematizando a questão ao diferenciar os tipos de livro entre raro, precioso e único. O conceito mais frágil seria o de livro único, que partiria do pressuposto da não existência de qualquer outro exemplar, o que pode parecer ingenuidade. A autora defende que todo livro precioso será um livro raro. Uma obra ou documento pode ser precioso para uma instituição - como a sua carta fundadora, por exemplo - e não possuir o mesmo valor para outra. Já na raridade se encontram os aspectos mencionados nos quatro grandes grupos acima. Segundo Pinheiro, a definição de raridade estaria "[...] na abordagem do caráter bibliológico das obras e na ênfase da influência social, econômica e cultural, sofrida por todas as autoridades que contribuíram na elaboração física e intelectual da obra." (PINHEIRO, 1989, p. 21).

Já Nardino e Caregnato (2005) definem Obras Raras como documentos que se destacam no mercado editorial, com características especiais que não possuem uma exata conexão com a época em que foram impressas, de modo que nem todo livro raro seja necessariamente um livro velho (NARDINO; CAREGNATO, 2005; PINHEIRO, 1989).

Contribuindo para o conceito de Obras Raras, Sant'Ana (2001) afirma que são principalmente livros, como também periódicos, mapas, folhas volantes, 
cartões-postais e outros materiais impressos. $\mathrm{O}$ autor descreve que existe uma discrepância na definição do conceito de "Obras Raras" entre colecionadores, bibliotecas e bibliotecários. Enquanto os primeiros “[...] não se prendem à antiguidade de uma obra para sua caracterização como rara, utilizando este termo mais como sinônimo de algo valioso [...]", os segundos “[...] referem-se à data como um dos principais critérios de raridade, reconhecendo na obra sua possibilidade de uso e não simples valor monetário." (SANT'ANA, 2001, p. 2).

No Dicionário de Cunha e Cavalcanti (2008, p. 234), um livro raro é aquele que, por diversas características especiais, intrínsecas ou extrínsecas, torna-se valioso, seja em função de sua edição, autógrafos, marcas de propriedade etc. Coube aqui, portanto, uma definição mais abrangente, mas não menos coesa. Contudo, uma coleção de Obras Raras de uma biblioteca deve se ater a critérios mais específicos e claros. Outra questão a se considerar é a especialização ou não de um acervo de Obras Raras. Segundo Greenhalgh (2011, p. 161), o foco de uma coleção de Obras Raras pode ser “[...] em uma área do conhecimento, ou multidisciplinar, ambas seguindo os propósitos da instituição a (sic) qual está vinculada.", alinhando-se sempre ao seu objetivo geral de contribuir para a preservação dos itens ali presentes.

A partir dessa breve análise da literatura acerca do conceito de Obras Raras, percebe-se a importância que esse tipo de documento possui para um acervo de biblioteca ou mesmo para um acervo pessoal. A grande questão que se vem debatendo desde o início do século $\mathrm{XX}$ - o qual trouxe a abertura dos acervos bibliográficos aos usuários por meio das bibliotecas públicas - é de como permitir o acesso às Obras Raras sem prejudicar sua preservação e a manutenção de sua continuidade no seu papel de formação cultural humana.

\section{Curadoria digital e preservação digital de obras raras}

Uma das respostas encontradas a esse desafio foi o processo de digitalização das Obras Raras e sua disponibilização na web, universal e gratuita a todos, ao possibilitar "[...] o acesso ao conteúdo, sem a necessidade de manusear o original.” (GREENHALGH, 2011, p. 160). 
É manifesto que a preservação de um acervo de Obras Raras deve seguir vários critérios, como os que combatem pragas biológicas, fatores ambientais como a luz do sol e a artificial, o mobiliário e condições arquitetônicas. No entanto, o aspecto que mais deve ser levado em consideração é a deterioração de obras pelo próprio ser humano, que é capaz de produzir efeitos desastrosos em um livro raro com muito mais rapidez que uma broca ou raios ultravioleta.

Segundo Márdero Arellano (1998, p. 29), várias medidas internacionais mostram que as atividades de conservação e preservação de coleções devem fazer parte do "[...] processo de produção da informação técnico-científica em centros de pesquisas de universidades, pois elas suprem as condições desejáveis para que informação seja armazenada e utilizada ao longo do tempo [...]"; é imprescindível haver certo grau de preservação da informação dentro de bibliotecas, principalmente no contexto de coleções de Obras Raras. Segundo o autor, uma das medidas mais eficazes para atingir esse objetivo é a digitalização de Obras Raras, o que permite que algumas características intrínsecas ao status de rara não sejam obstáculo ao acesso, como sua fragilidade e raridade insubstituível, por exemplo.

As vantagens da digitalização de Obras Raras extrapolam a sua conservação. A digitalização pode possibilitar a visibilidade da instituição dentro do universo da rede; suprir a demanda de acesso ao setor de Obras Raras, restrito na maioria das bibliotecas; liberar o bibliotecário ou funcionário da biblioteca de acompanhar o usuário durante a consulta ao acervo - requisito seguido por grande parte das instituições por motivos de preservação e segurança; proporcionar a consulta simultânea a uma mesma obra por vários usuários, já que a internet permite esse tipo de acesso; a liberação de espaço dentro da unidade de informação, tendo em vista que não será mais necessária uma grande mesa ou um ambiente climatizado para se ter acesso à obra, dentre outros benefícios que esse tipo de modalidade de preservação pode fornecer às coleções de Obras Raras.

No entanto, necessário sublinhar que o processo de digitalização de Obras Raras não seria um fim em si no que tange à preservação desse tipo de documento. Márdero Arellano (1998) orienta que é necessário conservar 
também os documentos que passam pelo processo de digitalização. Outros autores, como Conway et al. (2011), afirmam que o grande desafio da preservação de informações digitais não é apenas preservar a base de dados que abriga as obras digitalizadas, mas também proporcionar o uso dessa coleção digital para os usuários e para a comunidade no futuro. Em função disso, o investimento de digitalizar um acervo deve trazer o ganho intelectual e cultural de preservação daquele conteúdo digitalizado, assim como o conhecimento sobre como ter acesso a esse conteúdo binário ao longo dos anos.

Segundo Ferreira (2006, p. 17), um documento ou material digital possui intrinsecamente um desafio estrutural que coloca em cheque sua longevidade: a necessidade de "um contexto tecnológico para que possa ser consumido de forma inteligível por um ser humano". Caso essa dependência tecnológica não seja gerida de forma eficaz, a preservação digital desse objeto digital ficará comprometida e não haverá mais a oportunidade de acesso à sua informação. Ainda segundo o autor, a designação de preservação digital seria:

[...] o conjunto de actividades ou processos responsáveis por garantir o acesso continuado a longo-prazo à informação e restante património cultural existente em formatos digitais. A preservação digital consiste na capacidade de garantir que a informação digital permanece (sic) acessível e com qualidades de autenticidade suficientes para que possa ser interpretada no futuro recorrendo a uma plataforma tecnológica diferente da utilizada no momento da sua criação. (FERREIRA, 2006, p. 20).

Portanto, não há como falar em preservação de Obras Raras por meio de sua digitalização sem discutir a preservação digital dessas digitalizações.

Segundo o CONARQ (2006), a preservação de documentos está concentrada tradicionalmente na obtenção da estabilidade do suporte da informação. Contudo, no que concerne os documentos digitais, conservar o suporte não significa conservar o conteúdo - como pode ser aplicado genericamente aos documentos físicos. Nos documentos ou objetos digitais, o foco da preservação deve estar na manutenção do acesso, a qual exige intervenção periódica no que se refere ao seu hardware, software e formato. 
Na mesma linha de pensamento, Yamaoka (2012) afirma que a garantia e a continuidade do acesso permanente ao patrimônio digital são objetivos da preservação digital. Segundo o autor, o patrimônio digital sofre dois tipos de ameaças: a técnica e a física. É notório que em acervos de Obras Raras digitalizadas também existam essas duas variáveis, que seriam a preservação dos hardwares e a criação e manutenção de políticas de preservação digital do acervo.

Mais recentemente, dentro desse campo se encontra um termo que engloba toda a gestão e manutenção de acesso aos objetos digitais de um acervo: a curadoria digital. Segundo Sayão e Sales (2012, p. 180), a curadoria digital teria o compromisso de preservar o dado científico, ou bibliográfico, e também a necessidade de se preservar a "capacidade que ele possui de transmitir conhecimento para uso futuro nas comunidades interessadas". Os autores ainda afirmam que um dos objetivos da curadoria digital é possibilitar ao usuário do presente e futuro estar munido de instrumentos que possibilitem a reutilização daqueles dados ou informações binários. Desta forma, a temática da preservação digital estaria inserida dentro desse grande campo da curadoria digital.

Segundo Sayão e Sales (2012), a redução da obsolescência digital, das ameaças ao valor informacional de longo prazo, a diminuição de duplicação de esforços na criação de dados e informações, a continuidade de acesso informacional e a sustentabilidade de dados digitais são alguns dos objetivos característicos da curadoria digital. Todos esses objetivos dialogam com a atual realidade e necessidade dos acervos digitais de Obras Raras em pequenos, médios e grandes portais da internet.

É preciso ter em mente - tanto o usuário quanto o profissional da informação e o pesquisador - que o acesso aos objetos digitais não é tão fácil de ser assegurado como o acesso aos físicos (SIEBRA et al., 2013). É necessário que se estabeleçam políticas voltadas para sua preservação digital, levando em conta todo o seu ciclo de vida e promovendo assim uma curadoria digital de efeito real e benéfico para o acervo digital.

\section{Metodologia}


O objetivo desse artigo é analisar como o acesso às Obras Raras digitalizadas é disponibilizado e estruturado dentro dos portais da amostra escolhida. Os objetivos específicos são alinhados ao geral, no sentido de pretender identificar as principais dificuldades encontradas no acesso às Obras Raras online, estabelecer diferenças entre fonte primária e versão digital das Obras Raras e sugerir critérios para a melhoria do acesso às Obras Raras no formato digital.

O esforço empenhado nesse estudo resulta em uma pesquisa descritiva que busca um perfil analítico da realidade de acesso dos sites escolhidos na amostra, a partir de uma observação científica (SERAKAN, 2003; CRESSWELL, 2010). A abordagem metodológica utilizada é a dos métodos mistos, visto que essa é uma forma de coleta de dados que pode ser sequencial e feita em um único estudo e prover um melhor entendimento do problema.

Os dados quantitativos e qualitativos foram coletados por meio do levantamento de informações contidas nos portais escolhidos. A análise desses dados é feita por meio de estatística inferencial, o que, segundo Kothari (2004), busca, a partir da amostra, realizar um panorama da população de estudo e descrevê-la por meio dos dados coletados.

Por fim, o horizonte temporal da pesquisa é o longitudinal, ou seja, a pesquisa é analisada em dois momentos. A primeira análise foi feita em 2010 (KAMA, 2010) e a segunda em 2015, resultando em um espaço de tempo de 5 anos. A escolha desse horizonte temporal traz benefícios científicos e qualitativos à pesquisa ao gerar duas análises descritivas de um mesmo fenômeno em momentos diferentes, o que possibilita ao pesquisador verificar a evolução dos critérios de acesso às Obras Raras aqui contemplados.

Os dados dessa pesquisa foram coletados de dez portais de bibliotecas digitais, escolhidos de acordo com os seguintes critérios: possuir acesso online e livre; acervo de Obras Raras digitalizado; ter como idiomas disponíveis para a leitura o português ou o inglês; ter certa visibilidade dentro do universo bibliotecário.

Os portais escolhidos para a pesquisa foram:

Quadro 1 - Bibliotecas digitais pesquisadas 


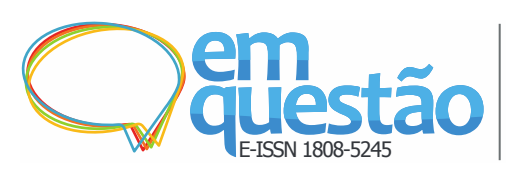

Análise de critérios e requisitos para o acesso a Obras Raras em bibliotecas digitais - um estudo longitudinal Ana Flávia Lucas de Faria Kama, Miriam Paula Manini, Dulce Maria Baptista

\begin{tabular}{|l|l|}
\hline \multicolumn{1}{|c|}{ Biblioteca Digital } & \multicolumn{1}{c|}{ Portal } \\
\hline Biblioteca digital de Obras Raras USP & http://www.obrasraras.usp.br/ \\
\hline Biblioteca Nacional Digital Brasil & http://bndigital.bn.br \\
\hline Biblioteca Mário de Andrade & http://docvirt.noip.com/demo/bma/bma.htm \\
\hline Biblioteca Digital do Senado Federal & http://www2.senado.leg.br/bdsf/ \\
\hline Biblioteca Digital da Câmara dos Deputados & http://bd.camara.gov.br/bd/ \\
\hline Biblioteca Nacional Digital Portugal & http://purl.pt/index/geral/PT/index.html \\
\hline Biblioteca Nacional Digital Escócia & http://digital.nls.uk/gallery.cfm \\
\hline Biblioteca Nacional da Inglaterra & http://www.bl.uk/reshelp/bldept/epc/earlyprinted/ \\
\hline Biblioteca Digital da Universidade de Cambridge & http://www.lib.cam.ac.uk/digital_image_collections \\
\hline Library of Congress - Coleções digitais & http://www.loc.gov/library/libarch-digital.html \\
\hline
\end{tabular}

Fonte: Dados da pesquisa.

\section{Pesquisa longitudinal}

Os critérios escolhidos para a coleta de dados desse estudo foram definidos em 2010, no primeiro momento da pesquisa, levando em conta aspectos que poderiam influenciar o acesso e a disponibilização de Obras Raras digitalizadas em portais na internet. Para que o estudo ficasse mais completo, na época decidiu-se inserir alguns critérios que levassem em conta também aspectos do acervo físico das instituições estudadas. Esses critérios foram elaborados da seguinte forma: ocorrência de link específico para Obras Raras; histórico da coleção; manual de acesso para o usuário; dimensões do portal e estatística de acessos às obras; temáticas predominantes do acervo; possibilidades de busca e recuperação do acervo; meios de contato com responsáveis pelo acervo; organização virtual e física do acervo de acordo com parâmetros profissionais da Biblioteconomia e possibilidades de acesso físico às obras ali digitalizadas.

Verificou-se a dificuldade em realizar a coleta de dados nos portais escolhidos. A primeira dificuldade encontrada no momento da segunda coleta foi a mudança dos endereços dos portais das bibliotecas selecionadas: ao todo, seis portais alteraram suas URLs. Outro problema recorrente foi a completa 
mudança no leiaute de alguns sites, como no caso da Biblioteca de Obras Raras da USP e a Biblioteca Mário de Andrade (na sua seção de Obras Raras). A internet é reconhecidamente um local virtual de mudanças e volatilidade de conteúdo, a começar pela própria URL do site, característica essa que seja, talvez, uma das grandes vantagens da rede em termos de conteúdo. Entretanto, em uma pesquisa como esta, é preciso levar em consideração essas alterações. Logo, alguns dados não puderam ser coletados novamente com total segurança, já que algumas seções e informações dos portais selecionados tinham certas informações em 2010 ausentes em 2015.

O primeiro bloco de critérios que foram comparados se refere ao acesso específico de Obras Raras digitalizadas nos portais. A maior evolução percebida foi na disponibilização de um manual de acesso para o usuário. $\mathrm{O}$ aumento percebido foi de 20\%, ou seja, enquanto que em 2010 apenas três sites forneciam um manual de acesso para o usuário, em 2015 cinco sites estavam disponibilizando este conteúdo. Esse critério é um dos mais interessantes de se analisar, tendo em vista que cada portal utiliza um software diferente para acesso às obras digitalizadas. Logo, é muito possível que o usuário não se sinta confortável em sua utilização. Desse conjunto de critérios, dois regrediram: a disponibilização do histórico do acervo digitalizado e o contato com os responsáveis por aquele acervo.

Quadro 2 - Critérios: dados das coleções digitalizadas

\begin{tabular}{|l|c|c|c|c|c|}
\hline \multirow{2}{*}{ Critérios } & \multicolumn{2}{|c|}{2010} & \multicolumn{2}{c|}{2015} & $\begin{array}{c}\text { Comparativo } \\
\text { 2010-2015 }\end{array}$ \\
\cline { 2 - 6 } & Possui & $\begin{array}{c}\text { Não } \\
\text { possui }\end{array}$ & Possui & $\begin{array}{c}\text { Não } \\
\text { possui }\end{array}$ & Avanço em possuir \\
\hline $\begin{array}{l}\text { Link específico para } \\
\text { Obras Raras }\end{array}$ & 5 & 5 & 6 & 4 & $10 \%$ \\
\hline Histórico do acervo & 8 & 2 & 7 & 3 & $-10 \%$ \\
\hline $\begin{array}{l}\text { Manual de acesso para } \\
\text { usuário }\end{array}$ & 3 & 7 & 5 & 5 & $20 \%$ \\
\hline Estatísticas & 2 & 8 & 3 & 7 & $10 \%$ \\
\hline $\begin{array}{l}\text { Contato com } \\
\text { responsáveis pelo acervo }\end{array}$ & 7 & 3 & 5 & 5 & $-20 \%$ \\
\hline
\end{tabular}

Fonte: Dados da pesquisa. 
As temáticas das obras digitalizadas também foram analisadas. Percebeu-se apenas o acréscimo do número de portais que inseriram novas temáticas: nenhum tema foi retirado das coleções, a única alteração sendo a inserção de novas obras com novos assuntos. Esse dado pode demonstrar que os acervos de Obras Raras digitalizadas tendem a crescer em sua variedade de temas, e que as obras que já foram digitalizadas e disponibilizadas na rede ainda permanecem importantes para os usuários dessas bibliotecas.

A temática que teve maior crescimento dentre as Obras Raras digitalizadas foi a de Legislação, seguida por Artes e Literatura. Partindo disso, pode-se afirmar que grande parte das Obras Raras digitalizadas dos sites pesquisados possui essas temáticas como algo predominante, ou que essas temáticas se tornaram ainda mais importantes nessas coleções.

Figura 1 - Temáticas predominantes

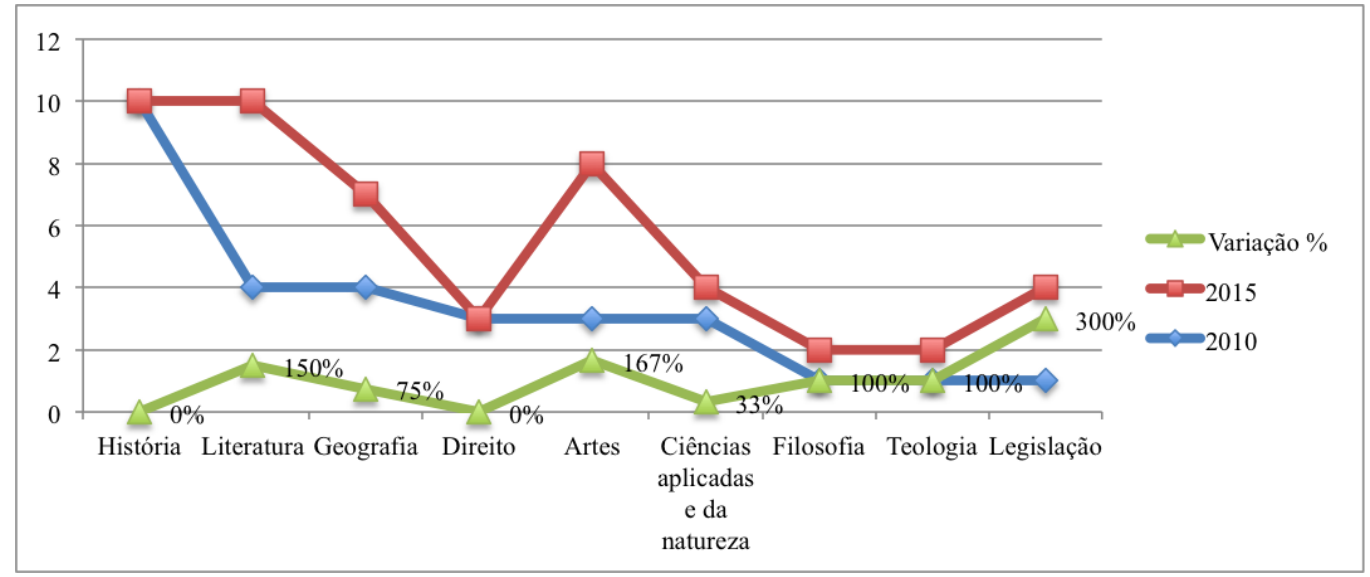

Fonte: Dados da pesquisa.

O critério "busca e recuperação" foi analisado a partir dos indicadores de avaliação "boa" e "regular". Todos os sites pesquisados possuem campo de pesquisa. Decidiu-se optar por esses dois indicadores de forma que o site que possuísse uma pesquisa completa e de fácil localização, logo na página inicial, tivesse a busca definida como "boa". Aqueles nos quais a pesquisa era demasiadamente simples, ou nos quais era preciso seguir para links a fim de realizar a pesquisa, foram definidos como "regular". Percebeu-se que esse critério teve um aumento em sua qualidade. Isso pode indicar o cuidado dos 
desenvolvedores do site em tornar as obras e as informações mais acessíveis aos usuários.

Quadro 3 - Critérios: busca e recuperação; organização virtual do acervo; organização física do acervo e acesso físico - tipo de usuário.

\begin{tabular}{|c|c|c|c|c|}
\hline Critérios & \multicolumn{2}{|c|}{2010} & \multicolumn{2}{|c|}{2015} \\
\hline \multirow{2}{*}{$\begin{array}{l}\text { Busca e } \\
\text { recuperação }\end{array}$} & Boa & Regular & Boa & Regular \\
\hline & 6 & 4 & 7 & 3 \\
\hline \multirow{2}{*}{$\begin{array}{c}\text { Organização } \\
\text { virtual do } \\
\text { acervo }\end{array}$} & Padronizada & Sem padrão & Padronizada & Sem padrão \\
\hline & 5 & 5 & 8 & 2 \\
\hline \multirow{2}{*}{$\begin{array}{l}\text { Organização } \\
\text { física do } \\
\text { acervo }\end{array}$} & $\begin{array}{c}\text { Acervos } \\
\text { organizados }\end{array}$ & $\begin{array}{c}\text { Catálogo específico } \\
\text { de Obras Raras }\end{array}$ & $\begin{array}{c}\text { Acervos } \\
\text { organizados }\end{array}$ & $\begin{array}{c}\text { Catálogo específico } \\
\text { de Obras Raras }\end{array}$ \\
\hline & 10 & 3 & 10 & 4 \\
\hline \multirow{2}{*}{$\begin{array}{l}\text { Acesso físico - } \\
\text { tipo de usuário }\end{array}$} & Pesquisadores & Todos & Pesquisadores & Todos \\
\hline & 2 & 8 & 1 & 9 \\
\hline
\end{tabular}

Fonte: Dados da pesquisa.

Já na questão relacionada à organização virtual do acervo foi vista uma melhora significativa. Esse quesito levou em considerações os padrões técnicos de organização da informação e do conhecimento do campo da Biblioteconomia, como a descrição bibliográfica, a classificação e a visualização das obras. Dois indicadores foram usados: "padronizada" para aqueles portais que possuem certo padrão na disposição e disponibilização das informações sobre as obras e "sem padrão" para aqueles que identificam cada obra de uma maneira, ou cada coleção de uma forma diferente, sem um padrão constante para a apresentação das informações. Percebe-se que os portais mais organizados e com informações mais completas de seus itens são aqueles que organizaram suas informações em quadros ou fichas, no formato AACR2/Marc ou não. Dois portais passaram a ser considerados padronizados no segundo momento da pesquisa, gerando com isso uma predominância na organização dos acervos virtuais. Esse avanço pode facilitar muito a pesquisa e busca de características específicas das obras digitalizadas. 
Seguindo a mesma ideia do critério anterior, também foi analisando o quesito organização física do acervo de Obras Raras. Novamente, todas as bibliotecas foram classificadas como tendo um acervo físico de Obras Raras organizado em catálogos e catálogos online de acesso aberto (OPACs). Apenas uma biblioteca a mais forneceu em seu site um catálogo específico ou temático para Obras Raras. Esse critério foi escolhido para ser analisado tendo em vista o possível interesse do usuário em saber como a obra digitalizada daquela biblioteca virtual pode estar armazenada na biblioteca física correspondente, ou até mesmo comparar os metadados de um registro de uma obra já digitalizada com outra que ainda não passou por esse processo.

Em questão ao tipo de usuário que pode ter acesso às Obras Raras físicas, no segundo momento da coleta se percebeu um aumento na permissão de consulta de usuários comuns às Obras Raras originais. Esse item foi analisado para se traçar um paralelo entre a importância de se disponibilizar Obras Raras digitalizadas na internet e as bibliotecas que não permitem que usuários comuns tenham acesso aos seus acervos raros. No entanto, houve uma diminuição no número de bibliotecas que só permitem usuários especialistas terem acesso ao seu acervo de Obras Raras. Ainda que seja um avanço para a disseminação do conhecimento, isso acaba por gerar mais custos de segurança e manutenção para a biblioteca, que deverá ter uma política de visitação mais complexa ou uma estrutura de segurança e pessoal mais preparada.

Os outros itens analisados quanto ao acesso à obra rara física não tiveram seus dados contemplados em 100\% no segundo momento da pesquisa. Em 2010, seis das 10 bibliotecas permitiam o acesso às Obras Raras originais - já em 2015, apenas quatro delas permitiam. Isso pode mostrar uma maior precaução quanto ao item anterior, que demonstrou avanço quanto à questão do acesso a qualquer tipo de usuário a esse tipo de acervo. Outra questão que deve ser levada em consideração é quanto aos reincidentes casos de furtos de Obras Raras que ocorreram nos últimos anos no mundo, levando algumas bibliotecas a terem mais cuidado com seus preciosos livros raros (GREENHALGH; MANINI, 2015). 
Com relação ao acesso a outros formatos, em 2010 três das dez bibliotecas físicas correspondentes às digitais permitiam o acesso às Obras Raras em outros formatos, como microfichas e fac-símiles. Em 2015 esse número cresceu de modo que quatro das dez bibliotecas forneceram dados em seus portais informando que permitiam esse tipo de acesso.

Já quanto ao acesso às Obras Raras dependendo do estado da obra, houve um crescimento quanto à restrição do acesso ou quanto à própria disponibilização dessa informação. Em 2015 metade das dez bibliotecas explicitaram essa informação em seus sites, enquanto que em 2010 apenas uma informava esse detalhe.

Quadro 4 - Critérios: acesso físico às Obras Raras

\begin{tabular}{|l|c|c|}
\hline \multicolumn{3}{|c|}{ Acesso físico às obras digitalizadas } \\
\hline & $\mathbf{2 0 1 0}$ & $\mathbf{2 0 1 5}$ \\
\hline Obras originais & 6 & 4 \\
\hline Outros formatos & 3 & 4 \\
\hline Depende do estado da obra & 1 & 5 \\
\hline
\end{tabular}

Fonte: Dados da pesquisa.

\section{Conclusões}

Em pleno mundo virtual, tomado pelas redes sociais e por certa artificialidade nas relações humanas, as coleções de Obras Raras podem ser vistas como um dos instrumentos de suporte à realidade sobre o que mundo foi, é e ainda poderá ser. São esses acervos que nos mostram características históricas e sociais que nos tornam parte de um grupo humano, que possui uma trajetória conjunta em um planeta comum. Em função disso, é urgente que cada vez mais esse tipo de acervo esteja em vias de desenvolvimento, de preservação e, principalmente, de acesso aos usuários interessados em seu conteúdo, já que é por meio da (re) ligação com nosso passado e presente - precioso, raro ou único - que podemos continuar construindo nossa história.

No entanto, seguir com as mesmas técnicas de preservação e processamento técnico que sempre existiram dentro das bibliotecas para esse tipo de acervo não basta. A pesquisa longitudinal exposta nesse artigo mostrou 
que novas tecnologias, atreladas à preservação digital e à curadoria digital, são e serão bem-vindas, contribuindo para a longevidade e segurança das coleções de Obras Raras ao redor do mundo.

Digitalizar uma obra rara e disponibilizá-la na internet não se trata apenas de mais um processo profissional dentro do ciclo documentário de uma unidade de informação, mas da possibilidade de tornar um documento especial ou único acessível ao maior número de pessoas possível. A potência desse ato é incalculável, contudo é preciso que hajam critérios e estudos coesos para que esse empreendimento seja realizado da melhor maneira possível.

Diante dos resultados dessa pesquisa foi possível perceber que esforços coerentes estão sendo empregados no processo de disponibilização de Obras Raras na internet. É possível analisar isso tendo em vista o aumento do número de temas representados nas coleções digitais de Obras Raras, o maior cuidado com informações disponibilizadas aos usuários desses portais e a padronização das pesquisas e dos metadados das obras digitalizadas.

É preciso citar também que não só o empenho dos profissionais da área e das instituições foi fundamental para a melhora na disponibilização de acervos de Obras Raras na internet, mas que de 2010 para 2015 também houve um crescimento imensurável nas tecnologias de rede e da internet. $\mathrm{O}$ fato da banda larga se tornar uma realidade para vários países, de novos gadgets serem disponibilizados no mercado de forma mais popular e a maior familiarização no manuseio da internet em praticamente todas as faixas etárias são grandes aliados à evolução dos acervos analisados nos portais das bibliotecas digitais escolhidos nesse estudo.

Portanto, diante do estudo analisado e das informações obtidas, fica latente a importância da continuação dos estudos na área de digitalização de Obras Raras, de preservação digital e no campo de desenvolvimento de bibliotecas digitais. Estudos futuros, com amostras diferenciadas e novos critérios, poderão ajudar na construção de um arcabouço literário para a manutenção e difusão da prática de digitalização de Obras Raras, sempre de maneira profissional e coesa. 


\section{Referências}

CONSELHO NACIONAL DE ARQUIVOS (Brasil). e-ARQ Brasil: modelos de requisitos para sistemas informatizados de gestão arquivística de documentos. Rio de Janeiro: CONARQ, 2006. Disponível em:

<http://www.uel.br/cch/cdph/arqtxt/downloads_e_ARQ.pdf>. Acesso em: 6 abr. 2016.

CONWAY, Esther et al. Curating scientific research data for the long term: a preservation analysis method in context. The International Journal of Digital Curation, Edinburgh, v. 6, n. 2, p. 38-52, 2011. Disponível em: <http://www.ijdc.net/index.php/ijdc/article/view/182/264>. Acesso em: 4 abr. 2016.

CRESWELL, J. W. Projeto de pesquisa: métodos qualitativo, quantitativo e misto. 3. ed. Porto Alegre: Artmed, 2010.

CUNHA, M. B. da; CAVALCANTI, C. R. de O. Dicionário de Biblioteconomia e Arquivologia. Brasília: Briquet de Lemos Livros, 2008.

FERREIRA, Miguel. Introdução à preservação digital: conceitos, estratégias e atuais consensos. Guimarães: Escola de Engenharia da Universidade do Minho, 2006. 85 p. Disponível em:

<https://repositorium.sdum.uminho.pt/bitstream/1822/5820/1/livro.pdf $>$. Acesso em: 06 abr. 2016.

GREENHALGH, R. D. Digitalização de obras raras: algumas considerações. Perspectivas em Ciência da Informação, Belo Horizonte, v. 16, n. 3, p. 159167, jul./set. 2011. Disponível em: <http://www.scielo.br/scielo.php?pid=

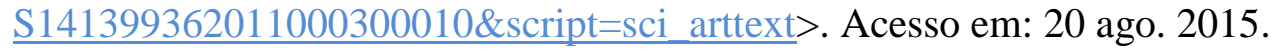

GREENHALGH, R. D.; MANINI, M. P. Análise bibliológica: ferramenta de segurança em coleções de livros raros. Encontros Bibli: Revista Eletrônica de Biblioteconomia e Ciência da Informação, Florianópolis, v. 20, n. 42, p. 17-29, jan./abr. 2015. Disponível em: <https://periodicos.ufsc.br/index. php/eb/article/download/1518-2924.2015v20n42p17/29133>. Acesso em: 20 dez. 2015.

KAMA, A. F. L. F. Análise e requisitos para o acesso a obras raras em bibliotecas digitais. 2010. $63 \mathrm{f}$. Monografia (Bacharelado em Biblioteconomia) - Departamento de Ciência da Informação e Documentação, Universidade de Brasília, Brasília, 2010. Disponível em: <http://bdm.unb.br/handle/10483/ 2147>. Acesso em: 20 ago. 2105.

KOTHARI, C. R. Research methodology: methods \& techniques. 2. ed. New Delhi: New Age International, 2004. 
MÁRDERO ARELLANO, Miguel Á. As coleções de obras raras na biblioteca digital. 1998. 100 f. Dissertação (Mestrado em Ciência da Informação) - Departamento de Ciência da Informação e Documentação, Universidade de Brasília, Brasília, 1998. Disponível em:

<http://hdl.handle.net/10482/152>. Acesso em: 10 out. 2015.

NARDINO, A. T. D.; CAREGNATO, S. E. O futuro dos livros do passado: a biblioteca digital contribuindo na preservação e acesso às obras raras. Em Questão, Porto Alegre, v. 11, n. 2, p. 381-407, jul./dez. 2005. Disponível em: <http://seer.ufrgs.br/index.php/EmQuestao/article/view/126/84>. Acesso em: 29 maio 2016.

PINHEIRO, A. V. T. da P. O que é livro raro? Uma metodologia para o estabelecimento de critérios de raridade bibliográfica. Rio de Janeiro: Presença Edições; Brasília: INL, 1989.

SANT'ANA, R. B. Critérios para a definição de obras raras. Revista Online Biblioteca Prof. Joel Martins, Campinas, v. 2, n. 3, p. 1-18, jun. 2001. Disponível em: <http://www.fe.unicamp.br/revista/index.php/etd/article/view Article/188 6>. Acesso em: 20 jul. 2015.

SAYÃO, L. F.; SALES, L. F. Curadoria digital: um novo patamar para preservação de dados digitais de pesquisa. Informação \& Sociedade, João Pessoa, v. 22, n. 3, p. 179-191, set./dez. 2012. Disponível em:

<https://www.icict.fiocruz.br/sites/www.icict.fiocruz.br/files/Curadoria\%20digit al_Luis\%20Fernando\%20Sayao.pdf>. Acesso em: 4 abr. 2016.

SERAKAN, Uma. Research methods for business: a skill-building approach. 4. ed. New York: John Wiley \& Sons, 2003.

SIEBRA, S. de A. et al. Curadoria digital: além da questão da preservação digital. In: ENCONTRO NACIONAL DE PESQUISA EM CIÊNCIA DA INFORMAÇÃO, 14., 2013, Rio de Janeiro. Anais... Rio de Janeiro, 2013. Disponível em: <http://www.egov.ufsc.br/portal/sites/default/files/curadoria_digital_0.pdf>. Acesso em: 06 abr. 2016.

THOMPSON, E. P. Costumes em comum: estudos sobre a cultura popular e tradicional. São Paulo: Companhia das Letras, 1998.

YAMAOKA, E. J. Ontologia para mapeamento da dependência tecnológica de objetos digitais no contexto da curadoria e preservação digital. AtoZ, Curitiba, v. 1, n. 2, p. 65-78, jan./dez. 2012. Disponível em:

<http://revistas.ufpr.br/atoz/article/view/41313>. Acesso em: 06 abr. 2016. 


\title{
Analysis of criteria and requirements to access in Rare Books digital libraries - a longitudinal study
}

\begin{abstract}
Rare book collections are of utmost importance to historical human knowledge. Through the years, scanning this type of collection and its availability has been turned into an effective alternative to its access, before the advances in digital preservation and digital curation. The present paper aims to analyze access criteria and requirements to scanned rare books in ten digital libraries in Brazil and the world. This is a mixed methodology longitudinal study. Data collection was conducted in 2010 and 2015 within the selected sample. The results obtained reveal the improvement in the quality of access and treatment of scanned rare books present at the sample. It can be concluded from the study that rare book scanning has obtained an improvement in quality. The procedure is being done in a more cohesive manner with more standardized requirements.
\end{abstract}

Keywords: Rare Books. Scanning. Rare Book Librarianship. Digital library. Digital preservation. Digital curation.

Recebido: 22/02/2016

Aceito: 24/05/2016 